\title{
Evaluation about the Performance of E-Government Based on Interval-Valued Intuitionistic Fuzzy Set
}

\author{
Shuai Zhang, Dejian Yu, Yan Wang, and Wenyu Zhang \\ School of Information, Zhejiang University of Finance and Economics, Hangzhou 310018, China \\ Correspondence should be addressed to Dejian Yu; yudejian62@126.com
}

Received 18 September 2013; Accepted 7 January 2014; Published 23 February 2014

Academic Editors: F. Di Martino and F. Schwenker

Copyright ( 2014 Shuai Zhang et al. This is an open access article distributed under the Creative Commons Attribution License, which permits unrestricted use, distribution, and reproduction in any medium, provided the original work is properly cited.

\begin{abstract}
The evaluation is an important approach to promote the development of the E-Government. Since the rapid development of EGovernment in the world, the E-Government performance evaluation has become a hot issue in the academia. In this paper, we develop a new evaluation method for the development of the E-Government based on the interval-valued intuitionistic fuzzy set which is a powerful technique in expressing the uncertainty of the real situation. First, we extend the geometric Heronian mean (GHM) operator to interval-valued intuitionistic fuzzy environment and proposed the interval-valued intuitionistic fuzzy GHM (IIFGHM) operator. Then, we investigate the relationships between the IIFGHM operator and some existing ones, such as generalized interval-valued intuitionistic fuzzy HM (GIIFHM) and interval-valued intuitionistic fuzzy weighted Bonferoni mean operator. Furthermore, we validate the effectiveness of the proposed method using a real case about the E-Government evaluation in Hangzhou City, China.
\end{abstract}

\section{Introduction}

Intuitionistic fuzzy set (IFS), an extension of Zadeh's fuzzy set, was first proposed by Atanassov [1]. Over the last decade, the IFS theory issue has become an important research area of mathematics, management, and computer sciences. It is generally known that the membership degree and nonmembership degree of the IFS are expressed by determined number [2-10]. Based on the IFS theory, Atanassov and Gargov [11] utilized the interval number rather than the determined number to express the membership degree and nonmembership degree and introduced the interval-valued IFS (IIFS). Researchers have many research works and have some results regarding IIFS theory.

Interval-valued intuitionistic fuzzy number (IIFN) is the basic ingredient of the IIFS theory and more powerful to express the uncertainty than intuitionistic fuzzy number (IFN) [12-14]. How to aggregate the IIFNs to a comprehensive one is a very active research area and is critical for artificial intelligence, decision making, and management science. So far there are many aggregation operators proposed to aggregate the IIFNs [15-17]. The Heronian mean (HM) is a mean type information aggregation technique, which is proposed by Beliakov et al. [18] and mainly used to aggregate determined numbers. In this paper, we extend the HM mean operator to adapt it to interval-valued intuitionistic fuzzy environment and then study the E-Government evaluation method based on IIFS theory.

To do this, we organize the paper as follows. Section 2 extends the GHM operator to interval-valued intuitionistic fuzzy environment and proposes the interval-valued intuitionistic fuzzy GHM (IIFGHM) operator. Some special cases are discussed in this section. Section 3 introduces the interval-valued intuitionistic fuzzy geometric weighted Heronian mean (IIFGWHM) and develops an approach for multicriteria decision making. A real case about the EGovernment evaluation in Hangzhou City, China, is also provided in this section. Section 4 ends this paper with some concluding remarks.

\section{The Interval-Valued Intuitionistic Fuzzy Geometric Heronian Mean Operator}

Atanassov and Gargov [11] first proposed the IIFS and gave the definition of IIFS. 
Definition 1. The IIFS $A$ on $X$ was defined as follows:

$$
A=\left\{\left\langle x, \tilde{t}_{A}(x), \tilde{f}_{A}(x)\right\rangle \mid x \in X\right\} .
$$

The $\tilde{t}_{A}(x)$ and $\tilde{f}_{A}(x)$ are two functions that indicated the degrees range of membership and nonmembership, respectively. Furthermore, the two functions are valued between $[0,1]$ and the sum of the maximum value of the two functions is also between $[0,1][19]$.

Definition 2 (see [20]). Let $\widetilde{\alpha}_{1}=\left(\left[a_{1}, b_{1}\right],\left[c_{1}, d_{1}\right]\right)$ and $\widetilde{\alpha}_{2}=$ $\left(\left[a_{2}, b_{2}\right],\left[c_{2}, d_{2}\right]\right)$ be any two IIFNs; then some operational rules of IIFN $\widetilde{\alpha}_{1}$ and IIFN $\widetilde{\alpha}_{2}$ are defined as

(1) $\tilde{\alpha}_{1} \oplus \tilde{\alpha}_{2}=\left(\left[a_{1}+a_{2}-a_{1} a_{2}, b_{1}+b_{2}-b_{1} b_{2}\right],\left[c_{1} c_{2}, d_{1} d_{2}\right]\right)$;

(2) $\widetilde{\alpha}_{1} \otimes \widetilde{\alpha}_{2}=\left(\left[a_{1} a_{2}, b_{1} b_{2}\right],\left[c_{1}+c_{2}-c_{1} c_{2}, d_{1}+d_{2}-d_{1} d_{2}\right]\right)$;

(3) $\lambda \widetilde{\alpha}_{1}=\left(\left[1-\left(1-a_{1}\right)^{\lambda}, 1-\left(1-b_{1}\right)^{\lambda}\right],\left[c_{1}^{\lambda}, d_{1}^{\lambda}\right]\right), \lambda>0$;

(4) $\widetilde{\alpha}_{1}^{\lambda}=\left(\left[a_{1}^{\lambda}, b_{1}^{\lambda}\right],\left[1-\left(1-c_{1}\right)^{\lambda}, 1-\left(1-d_{1}\right)^{\lambda}\right]\right), \lambda>0$.

And the score function of IIFN $\widetilde{\alpha}_{1}$ is defined as

$$
s\left(\widetilde{\alpha}_{1}\right)=\frac{a_{1}+b_{1}-c_{1}-d_{1}}{2} .
$$

The score function of IIFN is an important indicator for comparing any two IIFNs. In the general case, the bigger the score function, the bigger the IIFN.

Example 3. Let $\widetilde{\alpha}_{1}=([0.5,0.6],[0.2,0.3]), \widetilde{\alpha}_{2}=([0.1,0.3]$, $[0.4,0.6])$, and $\widetilde{\alpha}_{3}=([0.3,0.6],[0.3,0.2])$ be three IIFNs; we can get the following score functions based on (2)

$$
\begin{aligned}
& s\left(\widetilde{\alpha}_{1}\right)=\frac{0.5+0.6-0.2-0.3}{2}=0.3, \\
& s\left(\widetilde{\alpha}_{2}\right)=\frac{0.1+0.3-0.4-0.6}{2}=-0.3, \\
& s\left(\widetilde{\alpha}_{3}\right)=\frac{0.3+0.6-0.3-0.2}{2}=0.2 .
\end{aligned}
$$

Since

$$
s\left(\widetilde{\alpha}_{1}\right)>s\left(\widetilde{\alpha}_{3}\right)>s\left(\widetilde{\alpha}_{2}\right),
$$

then

$$
\tilde{\alpha}_{1}>\widetilde{\alpha}_{3}>\widetilde{\alpha}_{2}
$$

Heronian mean (HM) is able to characterize quantitatively the relations between the aggregated arguments. The definition of HM was given as follows.

Definition 4 (see [18]). Let $a_{i}(i=1,2, \ldots, n)$ be a collection of nonnegative numbers. If

$$
\operatorname{HM}\left(a_{1}, a_{2}, \ldots, a_{n}\right)=\frac{2}{n(n+1)} \sum_{i=1}^{n} \sum_{j=i}^{n} \sqrt{a_{i} a_{j}},
$$

then $\mathrm{HM}$ is called the Heronian mean (HM).
Example 5. Let $a_{1}=2, a_{2}=3, a_{3}=4$ be three nonnegative numbers; based on the HM operator, we can get

$$
\begin{aligned}
& \operatorname{HM}\left(a_{1}, a_{2}, a_{3}\right) \\
& =\frac{2}{3(3+1)}(\sqrt{2 \times 2}+\sqrt{2 \times 3}+\sqrt{2 \times 4}+\sqrt{3 \times 3} \\
& +\sqrt{3 \times 4}+\sqrt{4 \times 4})=2.96
\end{aligned}
$$

Based on Definition 4, Yu [21] proposed the geometric Heronian mean as follows.

Definition 6. Let $p>0, q>0, a_{i}(i=1,2, \ldots, n)$ be a collection of nonnegative numbers. If

$$
\operatorname{GHM}\left(a_{1}, a_{2}, \ldots, a_{n}\right)=\frac{1}{p+q}\left(\prod_{i=1, j=i}^{n}\left(p a_{i}+q a_{j}\right)^{2 / n(n+1)}\right),
$$

then GHM is called the geometric Heronian mean (GHM).

In order to deal with the situation of interval-valued intuitionistic fuzzy environment, we extend the GHM and propose the interval-valued intuitionistic fuzzy GHM as follows.

Definition 7. Let $p>0, q>0, \tilde{\alpha}_{i}=\left(\left[a_{i}, b_{i}\right],\left[c_{i}, d_{i}\right]\right)(i=$ $1,2, \ldots, n)$ be a collection of IIFNs; if

$$
\begin{aligned}
& \operatorname{IIFGHM}\left(\widetilde{\alpha}_{1}, \tilde{\alpha}_{2}, \ldots, \widetilde{\alpha}_{n}\right) \\
& =\frac{1}{p+q}\left(\bigotimes_{i=1, j=i}^{n}\left(p \tilde{\alpha}_{i}+q \widetilde{\alpha}_{j}\right)^{2 / n(n+1)}\right),
\end{aligned}
$$

then IIFGHM is called the interval-valued intuitionistic fuzzy geometric Heronian mean (IIFGHM).

Based on the operational laws of the IIFNs described in Definition 2, we can derive the following results.

Theorem 8. Let $p>0, q>0, \widetilde{\alpha}_{i}=\left(\left[a_{i}, b_{i}\right],\left[c_{i}, d_{i}\right]\right)(i=$ $1,2, \ldots, n)$ be a collection of IIFNs; then the aggregated value by using the IIFGHM is also an IIFN, and

$$
\begin{array}{r}
\operatorname{IIFGHM}\left(\widetilde{\alpha}_{1}, \widetilde{\alpha}_{2}, \ldots, \widetilde{\alpha}_{n}\right) \\
=\left(\left[1-\left(1-\prod_{i=1, j=i}^{n}\left(1-\left(1-a_{i}\right)^{p}\right.\right.\right.\right. \\
\left.\left.\times\left(1-a_{j}\right)^{q}\right)^{2 / n(n+1)}\right)^{1 /(p+q)},
\end{array}
$$




$$
\begin{gathered}
1-\left(1-\prod_{i=1, j=i}^{n}\left(1-\left(1-b_{i}\right)^{p}\right.\right. \\
\left.\left.\left.\times\left(1-b_{j}\right)^{q}\right)^{2 / n(n+1)}\right)^{1 /(p+q)}\right], \\
{\left[\left(1-\prod_{i=1, j=i}^{n}\left(1-c_{i}^{p} c_{j}^{q}\right)^{2 / n(n+1)}\right)^{1 /(p+q)},\right.} \\
\left.\left.\left(1-\prod_{i=1, j=i}^{n}\left(1-d_{i}^{p} d_{j}^{q}\right)^{2 / n(n+1)}\right)^{1 /(p+q)}\right]\right)
\end{gathered}
$$

Proof. We can prove Theorem 8 by mathematical induction and the similar proof method can be referred to Yu [21].

We studied the interval-valued intuitionistic fuzzy Heronian mean and proposed the generalized interval-valued intuitionistic fuzzy HM (GIIFHM) in our previous works [22]. It should be noted that the GIIFHM operator is a kind of averaging mean operator and the IIFGHM proposed in this paper is a kind of geometric mean operator. We try to apply a numeric example in simulation in order to compare the IIFGHM and GIIFHM operators.

Example 9. Let $\widetilde{\alpha}_{1}=([0.7,0.8],[0.1,0.2]), \widetilde{\alpha}_{2}=([0.3,0.4]$, $[0.5,0.6])$, and $\tilde{\alpha}_{3}=([0.6,0.7],[0.2,0.3])$ be three IIFNs; when the parameters $p, q$ take different values, scores values are obtained based on IIFGHM and GIIFHM operators which are shown in Figures 1 and 2.

\section{Interval-Valued Intuitionistic Fuzzy Multicriteria Decision Making Based on IIFGWHM Operator}

The IIFGHM operator does not consider the weight of the aggregated arguments and it should be improved. In this section we first introduce the weighted form of IIFGHM (IIFGWHM) operator and then introduce a multicriteria decision making method based on IIFGWHM operator.

Definition 10. Let $\widetilde{\alpha}_{i}=\left(\left[a_{i}, b_{i}\right],\left[c_{i}, d_{i}\right]\right)(i=1,2, \ldots, n)$ be a collection of IIFNs and $w=\left(w_{1}, w_{2}, \ldots, w_{n}\right)^{T}$ be the weight vector of $\tilde{\alpha}_{i}(i=1,2, \ldots, n)$, where $w_{i}$ indicates the importance degree of $\alpha_{i}$, satisfying $w_{i}>0, i=1,2, \ldots, n$, and $\sum_{i=1}^{n} w_{i}=1$. If

$$
\begin{aligned}
& \operatorname{IIFGWHM}^{p, q}\left(\widetilde{\alpha}_{1}, \widetilde{\alpha}_{2}, \ldots, \widetilde{\alpha}_{n}\right) \\
& \quad=\frac{1}{p+q}\left(\bigotimes_{i=1, j=i}^{n}\left(\left(p \widetilde{\alpha}_{i}\right)^{w_{i}} \oplus\left(q \widetilde{\alpha}_{j}\right)^{w_{j}}\right)^{2 / n(n+1)}\right),
\end{aligned}
$$

then IIFGWHM is called the interval-valued intuitionistic fuzzy geometric weighted Heronian mean (IIFGWHM).

Similar to Theorem 8, Theorem 11 can be derived easily.

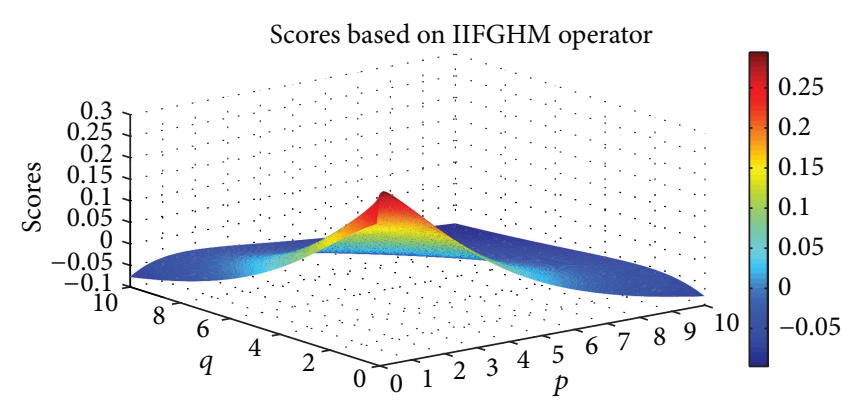

FIGURE 1: Scores obtained by the IIFGHM operator $(p \in(0,10]$, $q \in(0,10])$.

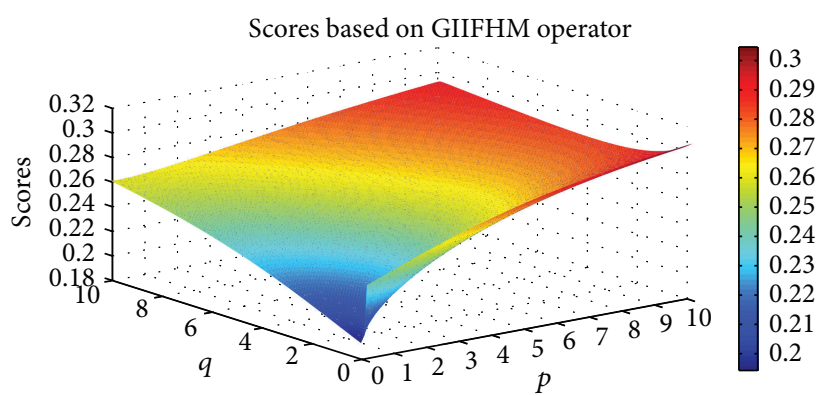

FIGURE 2: Scores obtained by the GIIFHM operator $(p \in(0,10]$, $q \in(0,10])$.

Theorem 11. Let $p>0, q>0, \tilde{\alpha}_{i}=\left(\left[a_{i}, b_{i}\right],\left[c_{i}, d_{i}\right]\right)(i=$ $1,2, \ldots, n)$ be a collection of IIFNs, whose weight vector is $w=$ $\left(w_{1}, w_{2}, \ldots, w_{n}\right)^{T}$, which satisfies $w_{i}>0, i=1,2, \ldots, n$, and $\sum_{i=1}^{n} w_{i}=1$. Then the aggregated value by using the IIFGWHM is also an IIFN, and

$$
\begin{aligned}
& \operatorname{IIFGWHM}\left(\widetilde{\alpha}_{1}, \widetilde{\alpha}_{2}, \ldots, \widetilde{\alpha}_{n}\right) \\
& =\left(\left[1-\left(1-\prod_{i=1, j=i}^{n}\left(1-\left(1-a_{i}^{w_{i}}\right)^{p}\right.\right.\right.\right. \\
& \left.\left.\times\left(1-a_{j}^{w_{j}}\right)^{q}\right)^{2 / n(n+1)}\right)^{1 /(p+q)} \\
& 1-\left(1-\prod_{i=1, j=i}^{n}\left(1-\left(1-b_{i}^{w_{i}}\right)^{p}\right.\right. \\
& \left.\left.\left.\times\left(1-b_{j}^{w_{j}}\right)^{q}\right)^{2 / n(n+1)}\right)^{1 /(p+q)}\right], \\
& {\left[\left(1-\prod_{i=1, j=i}^{n}\left(1-\left(1-\left(1-c_{j}\right)^{w_{i}}\right)^{p}\right.\right.\right.} \\
& \left.\left.\times\left(1-\left(1-c_{i}\right)^{w_{j}}\right)^{q}\right)^{2 / n(n+1)}\right)^{1 /(p+q)},
\end{aligned}
$$




$$
\begin{aligned}
\left(1-\prod_{i=1, j=i}^{n}\right. & \left(1-\left(1-\left(1-d_{i}\right)^{w_{i}}\right)^{p}\right. \\
& \left.\left.\left.\left.\times\left(1-\left(1-d_{j}\right)^{w_{j}}\right)^{q}\right)^{2 / n(n+1)}\right)^{1 /(p+q)}\right]\right) .
\end{aligned}
$$

In a presumed multicriteria decision making problem [23-29], let $A=\left\{A_{1}, A_{2}, \ldots, A_{m}\right\}$ be a set of $m$ Districts and let $C=\left\{c_{1}, c_{2}, \ldots, c_{n}\right\}$ a set of $n$ criteria, whose weight vector is $w=\left(w_{1}, w_{2}, \ldots, w_{n}\right)^{T}$, satisfying $w_{j}>0, j=$ $1,2, \ldots, n$ and $\sum_{j=1}^{n} w_{j}=1$. The performance of District $A_{i}$ with respect to the criterion $c_{j}$ is measured by an IIFN $\widetilde{\alpha}_{i j}=\left(\left[a_{i j}, b_{i j}\right],\left[c_{i j}, d_{i j}\right]\right)(i=1,2, \ldots, m ; j=1,2, \ldots, n)$, where $\left[a_{i j}, b_{i j}\right]$ indicates the degree range in which District $A_{i}$ satisfies the criterion $c_{j}$ and $\left[c_{i j}, d_{i j}\right]$ indicates the degree range in which District $A_{i}$ does not satisfy the criterion $c_{j}$ and construct the interval-valued intuitionistic fuzzy decision matrix $D=\left(\widetilde{\alpha}_{i j}\right)_{n \times m}$.

Step 1. Normalize the decision making matrix into standardized matrix. In other words, if the criteria $c_{j}$ is the benefit criteria, then the values do not need changing; if criteria $c_{j}$ is the cost criteria, then use $\overline{\widetilde{\alpha}}_{j}$ instead of $\widetilde{\alpha}_{j}[30-33]$, where $\overline{\widetilde{\alpha}}_{j}=$ $\left(\left[c_{j}, d_{j}\right],\left[a_{j}, b_{j}\right]\right)$ is the complement of $\widetilde{\alpha}_{j}=\left(\left[a_{j}, b_{j}\right],\left[c_{j}, d_{j}\right]\right)$.

Step 2. Aggregate all the performance values $\widetilde{\alpha}_{i j}(j=$ $1,2, \ldots, n)$ of the $i$ th line, and get the overall performance value $\widetilde{\alpha}_{i}$ corresponding to District $A_{i}$ by the IIFGWHM:

$$
\begin{aligned}
& \operatorname{IIFGWHM}{ }^{p, q}\left(\widetilde{\alpha}_{1}, \widetilde{\alpha}_{2}, \ldots, \widetilde{\alpha}_{n}\right) \\
& \quad=\frac{1}{p+q}\left(\bigotimes_{i=1, j=i}^{n}\left(\left(p \widetilde{\alpha}_{i}\right)^{w_{i}} \oplus\left(q \widetilde{\alpha}_{j}\right)^{w_{j}}\right)^{2 / n(n+1)}\right),
\end{aligned}
$$

where $p, q>0$.

Step 3. Rank the overall performance values $\widetilde{\alpha}_{i}(i=1,2$, $\ldots, m)$ according to Definition 2 and obtain the priority of Districts $A_{i}(i=1,2, \ldots, m)$ according to $\widetilde{\alpha}_{i}(i=1,2, \ldots, m)$.

Example 12. Advocating the E-Government has important value for establishing a harmonious and efficient government. Experience has confirmed the potential effect of EGovernment on the development of whole society. It is a fact to the academic circles that the continual development of E-Government needs the support of the performance evaluation. Hangzhou city is the capital of Zhejiang Province, China, and is the political, economic, cultural, and financial and transportation center of Zhejiang Province. At present, the performances of the E-Government of the four Districts $A_{i}(i=1,2, \ldots, 4)$ in Hangzhou city need to be evaluated. Based on the result of many researches [34, 35], this evaluation proceeds in the following three aspects: construction costs of the E-Government $\left(C_{1}\right)$, the effectiveness of the EGovernment system $\left(C_{2}\right)$, and the quality of E-Government system $\left(C_{3}\right)$. The three criteria may occur to different degrees

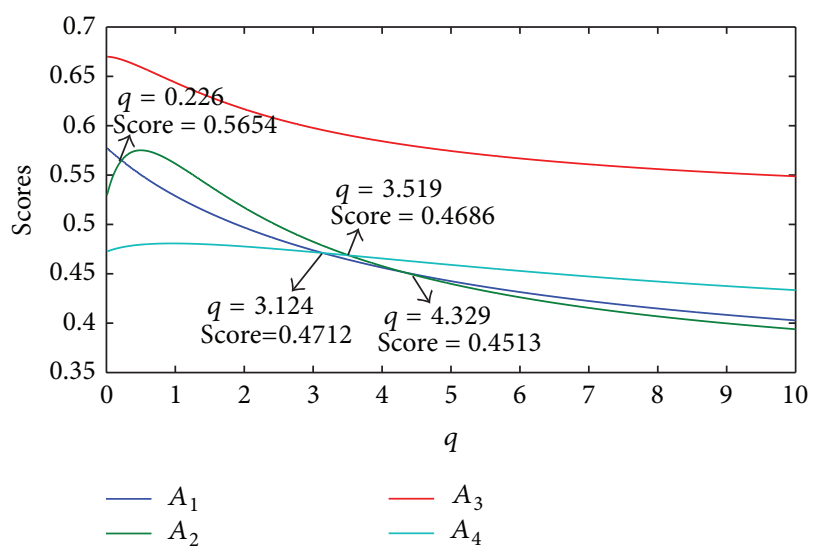

FIGURE 3: Scores of IIFWGHM $(p=1, q \in(0,10])$.

and suppose $(0.27,0.46,0.27)^{T}$ as the weight vector of the three criteria. The evaluation information on the four Districts $A_{i}(i=1,2, \ldots, 4)$ under the factors $C=\left\{c_{1}, c_{2}, c_{3}\right\}$ are represented by the IIFNs and shown in Table 1 .

Since the construction costs of the E-Government $\left(C_{1}\right)$ is the cost criteria, therefore, it needs normalization. The Normalized decision matrix is shown in Table 2.

From the Definition of IIFGWHM operator, we know that the values of parameters $p$ and $q$ may largely affect the aggregated IIFEs. In the following, we study the aggregated results as the values of the parameters $p$ and $q$ change. Tables 3 and 4 show the details of the results.

If we let the parameter $p(p=1)$ be fixed, different scores and rankings of the Districts can be obtained as the parameter $q$ changes, as is shown in Figure 3.

From Figure 3, we can find that,

(1) when $q \in(0,0.226]$, the ranking order of the Districts is $A_{3}>A_{1}>A_{2}>A_{4}$,

(2) when $q \in[0.226,3.124]$, the ranking order of the Districts is $A_{3}>A_{2}>A_{1}>A_{4}$,

(3) when $q \in[3.124,3.519]$, the ranking order of the Districts is $A_{3}>A_{2}>A_{4}>A_{1}$,

(4) when $q \in[3.519,4.329]$, the ranking order of the Districts is $A_{3}>A_{4}>A_{2}>A_{1}$,

(5) when $q \in[4.329,10.0]$, the ranking order of the Districts is $A_{3}>A_{4}>A_{1}>A_{2}$.

On the other hand, if we let the parameter $q(q=1)$ be fixed, different rankings of the Districts can be obtained as the parameter $p$ changed which was shown in Figure 4 .

From Figure 4, we can find that,

(1) when $q \in(0,0.05]$, the ranking order of the Districts is $A_{3}>A_{2}>A_{4}>A_{1}$,

(2) when $q \in[0.05,3.623]$, the ranking order of the Districts is $A_{3}>A_{2}>A_{1}>A_{4}$,

(3) when $q \in[3.623,4.341]$, the ranking order of the Districts is $A_{3}>A_{2}>A_{4}>A_{1}$, 
TABLE 1: The interval-valued intuitionistic fuzzy decision matrix $B$.

\begin{tabular}{lccc}
\hline & $C_{1}$ & $C_{2}$ & $C_{3}$ \\
\hline$A_{1}$ & $([0.2,0.3],[0.6,0.7])$ & $([0.2,0.4],[0.4,0.5])$ & $([0.1,0.3],[0.3,0.5])$ \\
$A_{2}$ & $([0.3,0.5],[0.1,0.3])$ & $([0.3,0.4],[0.4,0.6])$ & $([0.7,0.9],[0.0,0.1])$ \\
$A_{3}$ & $([0.4,0.6],[0.3,0.4])$ & $([0.7,0.9],[0.0,0.1])$ & $([0.2,0.3],[0.4,0.6])$ \\
$A_{4}$ & $([0.4,0.6],[0.2,0.3])$ & $([0.3,0.4],[0.4,0.5])$ & $([0.2,0.4],[0.4,0.5])$ \\
\hline
\end{tabular}

TABLE 2: The interval-valued intuitionistic fuzzy decision matrix $B$.

\begin{tabular}{lccc}
\hline & $C_{1}$ & $C_{2}$ & $C_{3}$ \\
\hline$A_{1}$ & $([0.6,0.7],[0.2,0.3])$ & $([0.2,0.4],[0.4,0.5])$ & $([0.1,0.3],[0.3,0.5])$ \\
$A_{2}$ & $([0.1,0.3],[0.3,0.5])$ & $([0.3,0.4],[0.4,0.6])$ & $([0.7,0.9],[0.0,0.1])$ \\
$A_{3}$ & $([0.3,0.4],[0.4,0.6])$ & $([0.7,0.9],[0.0,0.1])$ & $([0.2,0.3],[0.4,0.6])$ \\
$A_{4}$ & $([0.2,0.3],[0.4,0.6])$ & $([0.3,0.4],[0.4,0.5])$ & $([0.2,0.4],[0.4,0.5])$ \\
\hline
\end{tabular}

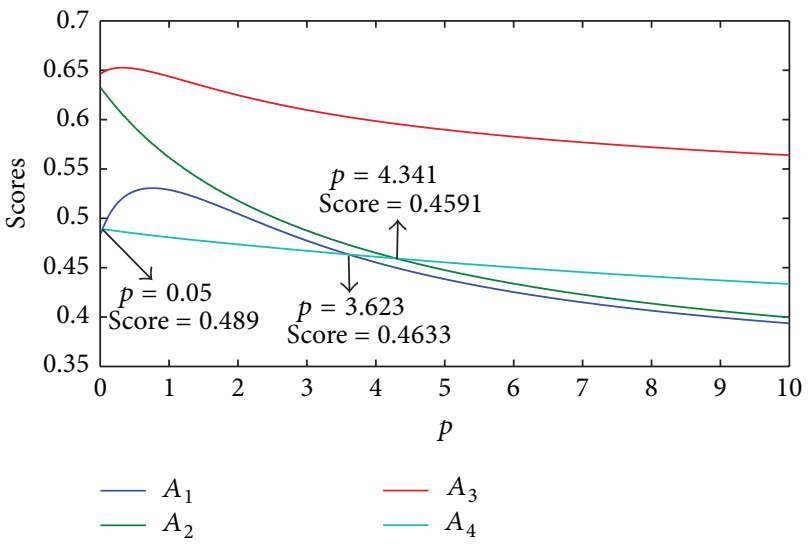

FIGURE 4: Scores of IIFGWHM $(q=1, p \in(0,10])$.

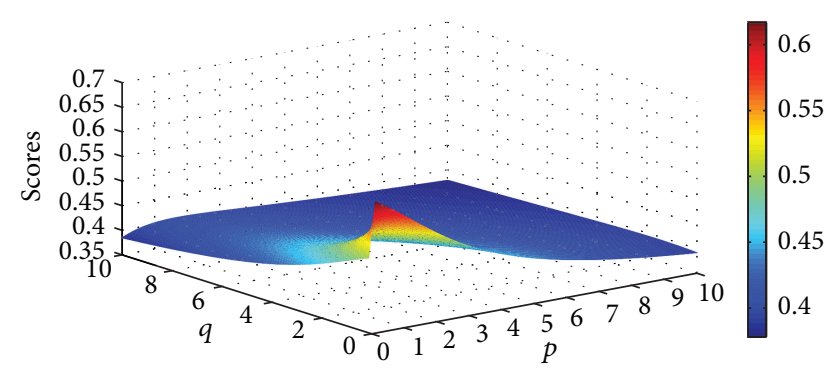

FIgURE 5: Scores for District $A_{1}$ obtained by the IIFGWHM operator $(p \in(0,6], q \in(0,6])$.

(4) when $q \in[4.341,10.0]$, the ranking order of the Districts is $A_{3}>A_{4}>A_{2}>A_{1}$.

Different scores of the four Districts can be obtained as the parameters $p$ and $q$ changed. Figures $5,6,7$, and 8 illustrate the scores of four Districts obtained by the IIFGWHM operator in detail.

From the above analysis, we can easily find that when the parameters are assigned different values, different decision results may be generated. Therefore, it is a very flexible interval-valued intuitionistic fuzzy decision making method.

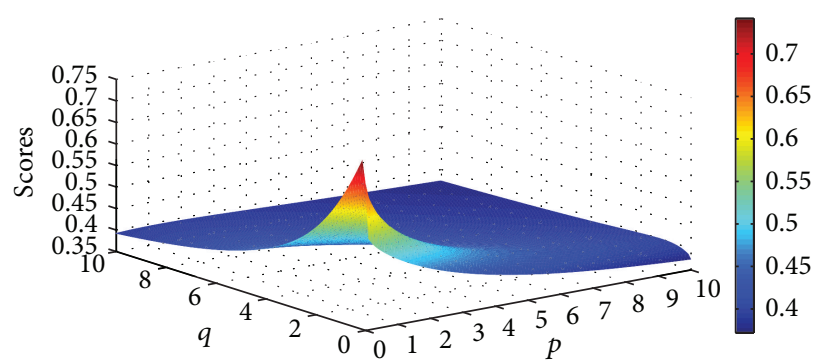

FIgURE 6: Scores for District $A_{2}$ obtained by the IIFGWHM operator $(p \in(0,6], q \in(0,6])$.

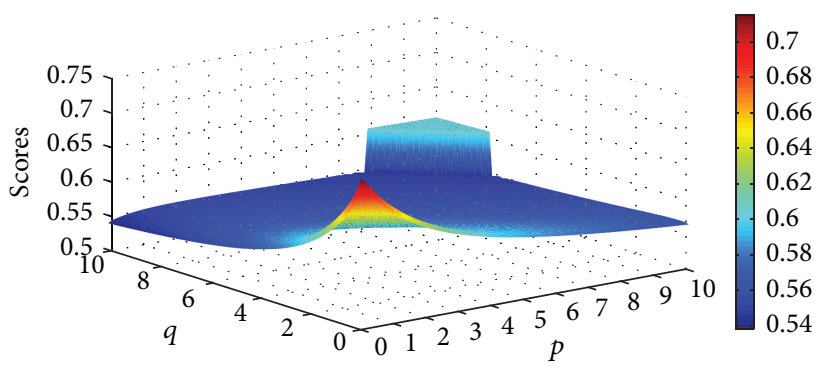

Figure 7: Scores for District $A_{3}$ obtained by the IIFGWHM operator $(p \in(0,6], q \in(0,6])$.

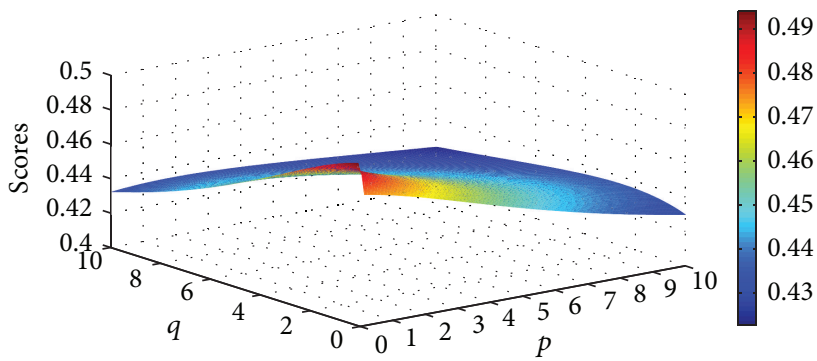

FIGURE 8: Scores for District $A_{4}$ obtained by the IIFGWHM operator $(p \in(0,6], q \in(0,6])$. 


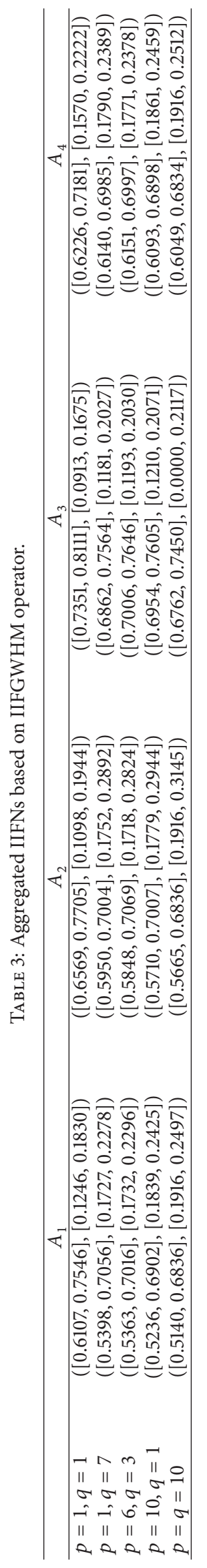


TABLE 4: Score values obtained by the IIFGWHM operator and the rankings of Districts.

\begin{tabular}{lccccc}
\hline & $A_{1}$ & $A_{2}$ & $A_{3}$ & $A_{4}$ & Ranking \\
\hline$p=1, q=1$ & 0.5288 & 0.5616 & 0.6437 & 0.4807 & $A_{3}>A_{2}>A_{1}>A_{4}$ \\
$p=1, q=7$ & 0.4224 & 0.4155 & 0.5609 & 0.4473 & $A_{3}>A_{4}>A_{1}>A_{2}$ \\
$p=6, q=3$ & 0.4176 & 0.4188 & 0.5715 & 0.4500 & $A_{3}>A_{4}>A_{2}>A_{1}$ \\
$p=10, q=1$ & 0.3937 & 0.3997 & 0.5640 & 0.4335 & $A_{3}>A_{4}>A_{2}>A_{1}$ \\
$p=q=10$ & 0.3781 & 0.3720 & 0.6048 & 0.4228 & $A_{3}>A_{4}>A_{1}>A_{2}$ \\
\hline
\end{tabular}

In order to compare the IIFGWHM operator with the IIFWBM operator which was proposed by Xu and Chen [33], we utilize the IIFWBM operator to replace (13) and analyze the decision making method. The IIFWBM operator was given as follows [33]:

$$
\begin{aligned}
& \operatorname{IIFWBM}\left(\widetilde{\alpha}_{1}, \widetilde{\alpha}_{2}, \ldots, \widetilde{\alpha}_{n}\right) \\
& \qquad\left(1-\prod_{\substack{i=1, j=1 \\
i \neq j}}^{n}\left(1-\left(1-\left(1-a_{i}\right)^{w_{i}}\right)^{p}\right.\right. \\
& \left.\left.\times\left(1-\left(1-a_{j}\right)^{w_{j}}\right)^{q}\right)^{1 / n(n-1)}\right)^{1 /(p+q)}, \\
& \left.\left(\begin{array}{c}
1-\prod_{\substack{i=1, j=1 \\
i \neq j}}^{n}\left(1-\left(1-\left(1-b_{i}\right)^{w_{i}}\right)^{p}\right. \\
\left.\times\left(1-\left(1-b_{j}\right)^{w_{j}}\right)^{q}\right)^{1 / n(n-1)}
\end{array}\right)^{1 /(p+q)}\right],
\end{aligned}
$$

$$
\begin{gathered}
{\left[1-\left(1-\prod_{\substack{i=1, j=1 \\
i \neq j}}^{n}\left(1-\left(1-c_{i}^{w_{i}}\right)^{p}\right.\right.\right.} \\
\left.\left.\times\left(1-c_{j}^{w_{j}}\right)^{q}\right)^{1 / n(n-1)}\right)^{1 /(p+q)}, \\
1-\left(1-\prod_{\substack{i=1, j=1 \\
i \neq j}}^{n}\left(1-\left(1-d_{i}^{w_{i}}\right)^{p}\right.\right. \\
\left.\left.\left.\left.\times\left(1-d_{j}^{w_{j}}\right)^{q}\right)^{1 / n(n-1)}\right)^{1 /(p+q)}\right]\right) .
\end{gathered}
$$

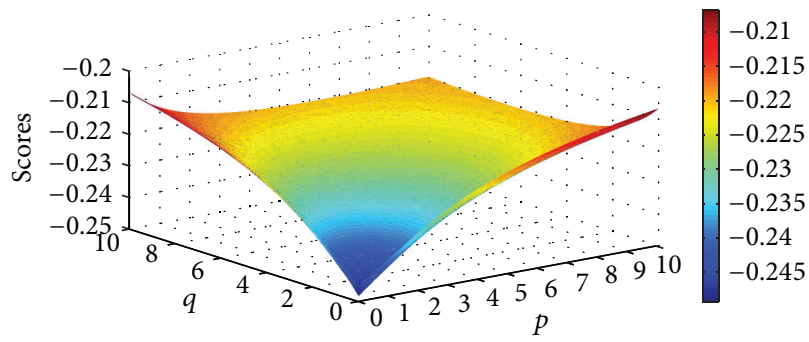

FIGURE 9: Scores for District $A_{1}$ obtained by the IIFWBM operator $(p \in(0,10], q \in(0,10])$.

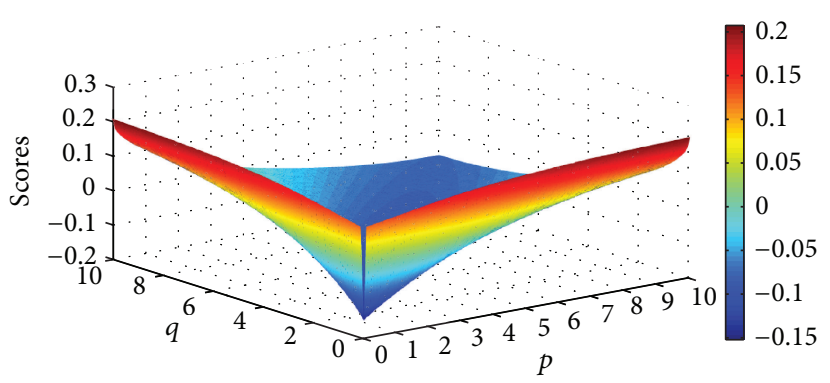

FIgURE 10: Scores for District $A_{2}$ obtained by the IIFWBM operator $(p \in(0,10], q \in(0,10])$.

If we aggregate the IIFNs based on the IIFWBM operator, the aggregated IIFNs can be obtained as the values of the parameters $p$ and $q$ change. The results are shown in Table 5 . The corresponding score values and the ranking of Districts are shown in Table 6.

Different scores of the four Districts can be obtained as the parameters $p$ and $q$ change. Figures $9,10,11$, and 12 illustrate the scores of four Districts obtained by the IFWBM operator in detail.

\section{Concluding Remarks}

In this paper, we have put forward an associated aggregation operator for IIFNs called the IIFGHM operator. We have analyzed the weighted form of IIFGHM operator and introduced the IIFGWHM operator. A flexible multicriteria decision making method has been introduced, by which the optimal alternative(s) can be derived. We have studied the applicability of the IIFGWHM operator in multicriteria decision making problems and we have carried out the evaluation of 


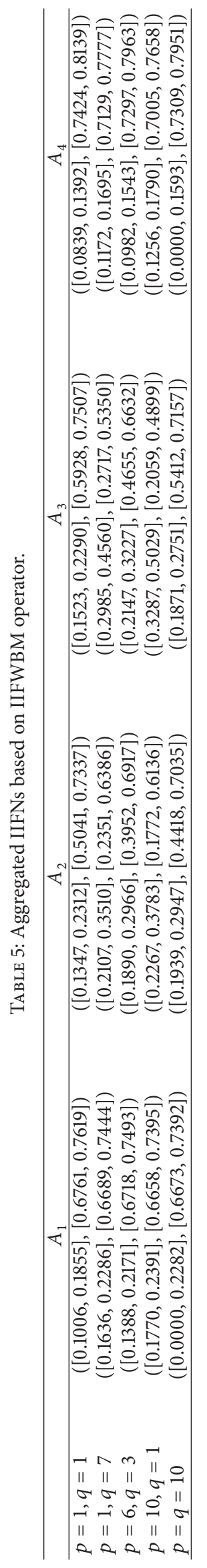


TABLE 6: Score values obtained by the IIFWBM operator and the rankings of Districts.

\begin{tabular}{lccccc}
\hline & $A_{1}$ & $A_{2}$ & $A_{3}$ & $A_{4}$ & Ranking \\
\hline$p=1, q=1$ & -0.2453 & -0.1364 & -0.1819 & -0.3016 & $A_{2}>A_{3}>A_{1}>A_{4}$ \\
$p=1, q=7$ & -0.2201 & 0.0579 & 0.0922 & -0.2717 & $A_{2}>A_{3}>A_{1}>A_{4}$ \\
$p=6, q=3$ & -0.2273 & -0.0493 & -0.0714 & -0.2877 & $A_{2}>A_{3}>A_{1}>A_{4}$ \\
$p=10, q=1$ & -0.2133 & 0.1006 & 0.1485 & -0.2608 & $A_{3}>A_{2}>A_{1}>A_{4}$ \\
$p=q=10$ & -0.2196 & -0.0735 & -0.1331 & -0.2858 & $A_{2}>A_{3}>A_{1}>A_{4}$ \\
\hline
\end{tabular}

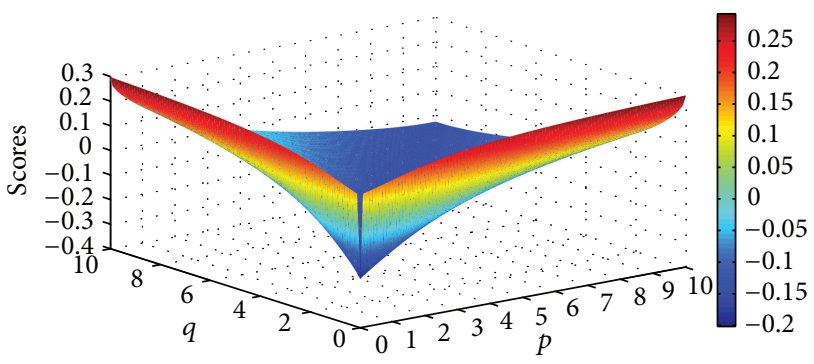

FIgURE 11: Scores for District $A_{3}$ obtained by the IIFWBM operator $(p \in(0,10], q \in(0,10])$.

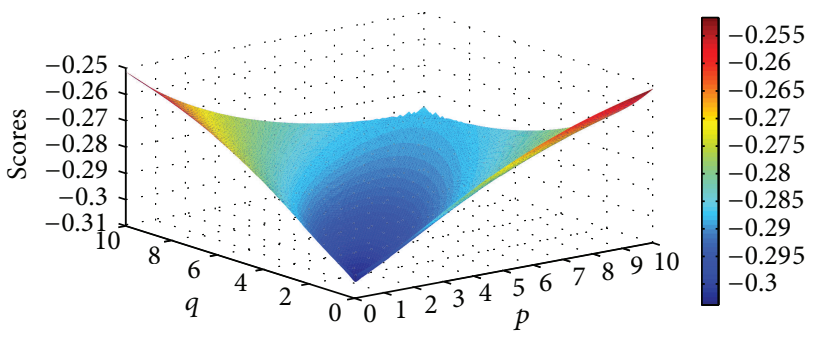

FIGURE 12: Scores for District $A_{4}$ obtained by the IIFWBM operator $(p \in(0,10], q \in(0,10])$.

the performance of E-Government in Hangzhou city, China. In future research, we will consider other applications of this approach, such as investment management, teaching quality evaluation, and supply chain management.

\section{Conflict of Interests}

The authors declare that there is no conflict of interests regarding the publication of this paper.

\section{Acknowledgment}

The authors would like to thank the anonymous reviewers for their valuable comments on their paper. This research was supported by the National Natural Science Foundation of China (nos. 71301142 and 51375429), the Zhejiang Natural Science Foundation of China (no. LQ13G010004), and the Zhejiang Science \& Technology Plan of China (no. 2013C31099).

\section{References}

[1] K. T. Atanassov, "Intuitionistic fuzzy sets," Fuzzy Sets and Systems, vol. 20, no. 1, pp. 87-96, 1986.

[2] Z. S. Xu, J. Chen, and J. J. Wu, "Clustering algorithm for intuitionistic fuzzy sets," Information Sciences, vol. 178, no. 19, pp. 3775-3790, 2008.

[3] D. J. Yu, Y. Y. Wu, and T. Lu, "Interval-valued intuitionistic fuzzy prioritized operators and their application in group decision making," Knowledge-Based Systems, vol. 30, pp. 57-66, 2012.

[4] Z. Y. Bai, "An interval-valued intuitionistic fuzzy TOPSIS method based on an improved score function," The Scientific World Journal, vol. 2013, Article ID 879089, 6 pages, 2013.

[5] L. L. Wang, D. F. Li, and S. S. Zhang, "Mathematical programming methodology for multiattribute decision making using interval-valued intuitionistic fuzzy sets," Journal of Intelligent and Fuzzy Systems, vol. 24, no. 4, pp. 755-763, 2013.

[6] D. F. Li and J. Yang, "A difference-index based ranking bilinear programming approach to solving bimatrix games with payoffs of trapezoidal intuitionistic fuzzy numbers," Journal of Applied Mathematics, vol. 2013, Article ID 697261, 10 pages, 2013.

[7] D. F. Li and S. P. Wan, "Fuzzy linear programming approach to multi-attribute decision making with multiple types of attribute values and incomplete weight information," Applied Soft Computing, vol. 13, no. 11, pp. 4333-4348, 2013.

[8] D. F. Li and F. X. Hong, "Alfa-cut based linear programming methodology for constrained matrix games with payoffs of trapezoidal fuzzy numbers," Fuzzy Optimization and Decision Making, vol. 12, no. 2, pp. 191-213, 2013.

[9] N. Çağman and S. Karataş, "Intuitionistic fuzzy soft set theory and its decision making," Journal of Intelligent and Fuzzy Systems, vol. 24, no. 4, pp. 829-836, 2013.

[10] E. Jafarian and M. A. Rezvan, "A valuation-based method for ranking the intuitionistic fuzzy numbers," Journal of Intelligent and Fuzzy Systems, vol. 24, no. 1, pp. 133-144, 2013.

[11] K. Atanassov and G. Gargov, "Interval valued intuitionistic fuzzy sets," Fuzzy Sets and Systems, vol. 31, no. 3, pp. 343-349, 1989.

[12] Z. S. Xu and R. R. Yager, "Dynamic intuitionistic fuzzy multiattribute decision making," International Journal of Approximate Reasoning, vol. 48, no. 1, pp. 246-262, 2008.

[13] Z. Xu and R. R. Yager, "Intuitionistic and interval-valued intutionistic fuzzy preference relations and their measures of similarity for the evaluation of agreement within a group," Fuzzy Optimization and Decision Making, vol. 8, no. 2, pp. 123-139, 2009.

[14] Z. S. Xu, "Intuitionistic fuzzy aggregation operators," IEEE Transactions on Fuzzy Systems, vol. 15, no. 6, pp. 1179-1187, 2007. 
[15] H. Zhao, Z. S. Xu, M. Ni, and S. Liu, "Generalized aggregation operators for intuitionistic fuzzy sets," International Journal of Intelligent Systems, vol. 25, no. 1, pp. 1-30, 2010.

[16] F. Y. Meng, C. Q. Tan, and Q. Zhang, "The induced generalized interval-valued intuitionistic fuzzy hybrid Shapley averaging operator and its application in decision making," KnowledgeBased Systems, vol. 42, pp. 9-19, 2013.

[17] W. Z. Wang and X. W. Liu, "The multi-attribute decision making method based on interval-valued intuitionistic fuzzy Einstein hybrid weighted geometric operator," Computers \& Mathematics with Applications, vol. 66, no. 10, pp. 1845-1856, 2013.

[18] G. Beliakov, A. Pradera, and T. Calvo, Aggregation Functions: A Guide for Practitioners, Springer, Berlin, Germany, 2007.

[19] Z.-S. Xu, "Methods for aggregating interval-valued intuitionistic fuzzy information and their application to decision making," Control and Decision, vol. 22, no. 2, pp. 215-219, 2007.

[20] W. J. Liu, Z. Z. Lin, F. S. Wen, and G. Ledwich, "Intuitionistic fuzzy Choquet integral operator-based approach for black-start decision making," Generation, Transmission \& Distribution, vol. 6, no. 5, pp. 378-386, 2012.

[21] D. J. Yu, "Intuitionistic fuzzy geometric Heronian mean aggregation operators," Applied Soft Computing, vol. 13, no. 2, pp. 1235-1246, 2013.

[22] D. J. Yu and Y. Y. Wu, "Interval-valued intuitionistic fuzzy Heronian mean operators and their application in multi-criteria decision making," African Journal of Business Management, vol. 6, no. 11, pp. 4158-4168, 2012.

[23] V. Cancer and M. Mulej, "Multi-criteria decision making in creative problem solving," Kybernetes, vol. 42, no. 1, pp. 67-81, 2013.

[24] Z. J. Chen, W. Z. Chen, and Q. L. Chen, "Group decision making based on the LCLR method," Kybernetes, vol. 39, no. 6, pp. 881$887,2010$.

[25] Z. Jian-Jun, L. Si-Feng, and L. Li-Hong, "Research on four kinds of uncertain preference information aggregation approach in group decision making," Kybernetes, vol. 38, no. 10, pp. 1862$1869,2009$.

[26] P. D. Liu, “The multi-attribute group decision making method based on the interval grey linguistic variables weighted aggregation operator," Journal of Intelligent and Fuzzy Systems, vol. 24, no. 20, pp. 405-414, 2013.

[27] D. J. Yu, "Group decision making based on generalized intuitionistic fuzzy prioritized geometric operator," International Journal of Intelligent Systems, vol. 27, no. 7, pp. 635-661, 2012.

[28] D. J. Yu, "Multi-criteria decision making based on generalized prioritized aggregation operators under intuitionistic fuzzy environment," International Journal of Fuzzy Systems, vol. 15, no. 1, pp. 47-54, 2013.

[29] D. J. Yu, "Prioritized information fusion method for triangular intuitionistic fuzzy set and its application to teaching quality evaluation," International Journal of Intelligent Systems, vol. 28, no. 5, pp. 635-661, 2013.

[30] Z. S. Xu, "Choquet integrals of weighted intuitionistic fuzzy information," Information Sciences, vol. 180, no. 5, pp. 726-736, 2010.

[31] Z.S. Xu, "Approaches to multiple attribute group decision making based on intuitionistic fuzzy power aggregation operators," Knowledge-Based Systems, vol. 24, no. 6, pp. 749-760, 2011.

[32] C. Q. Tan, "Generalized intuitionistic fuzzy geometric aggregation operator and its application to multi-criteria group decision making," Soft Computing, vol. 15, no. 5, pp. 867-876, 2011.

[33] Z. S. Xu and Q. Chen, "A multi-criteria decision making procedure based on interval-valued intuitionistic fuzzy bonferroni means," Journal of Systems Science and Systems Engineering, vol. 20, no. 2, pp. 217-228, 2011.

[34] J. H. Yan, G. L. Ning, and M. K. Sheng, "Synthetic evaluation about the performance of E-government based on neural network," Chinese Journal of Management Science, vol. 13, no. 6, pp. 125-130, 2005.

[35] T. Almarabeh and A. AbuAli, "A general framework for Egovernment: definition maturity challenges, opportunities, and success," European Journal of Scientific Research, vol. 39, no. 1, pp. 29-42, 2010. 

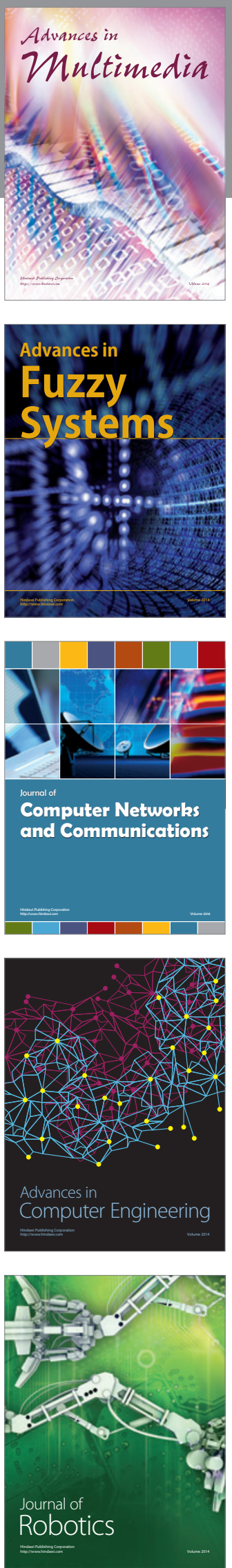

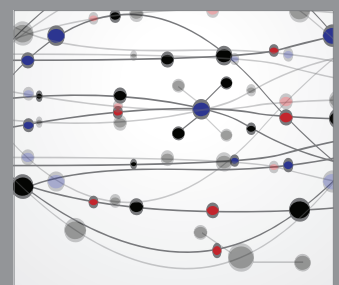

The Scientific World Journal
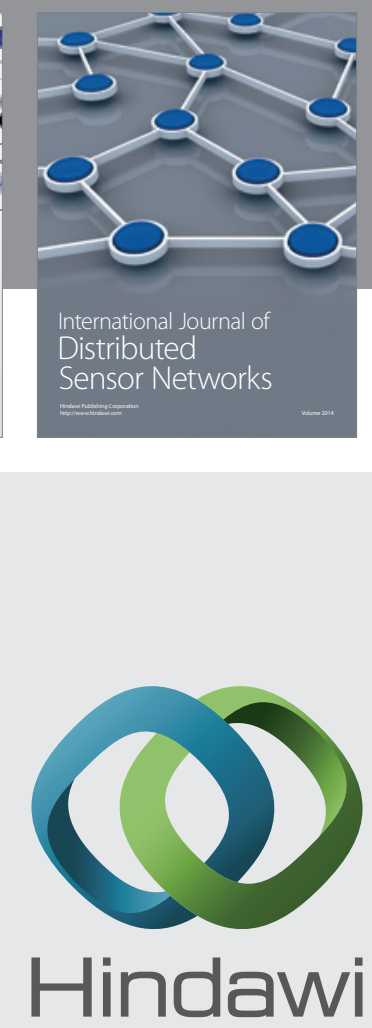

Submit your manuscripts at

http://www.hindawi.com
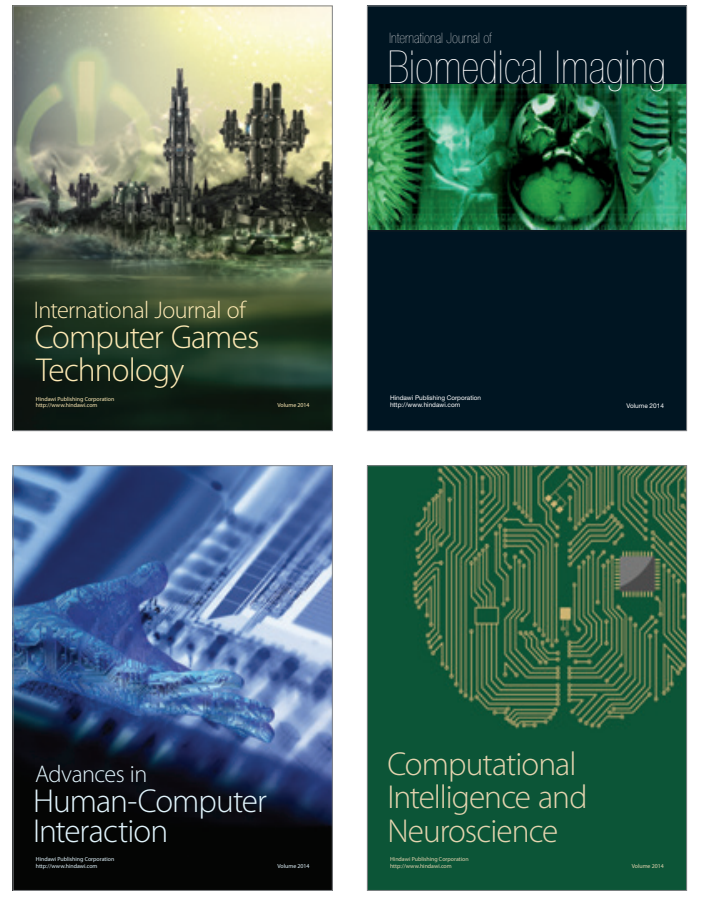
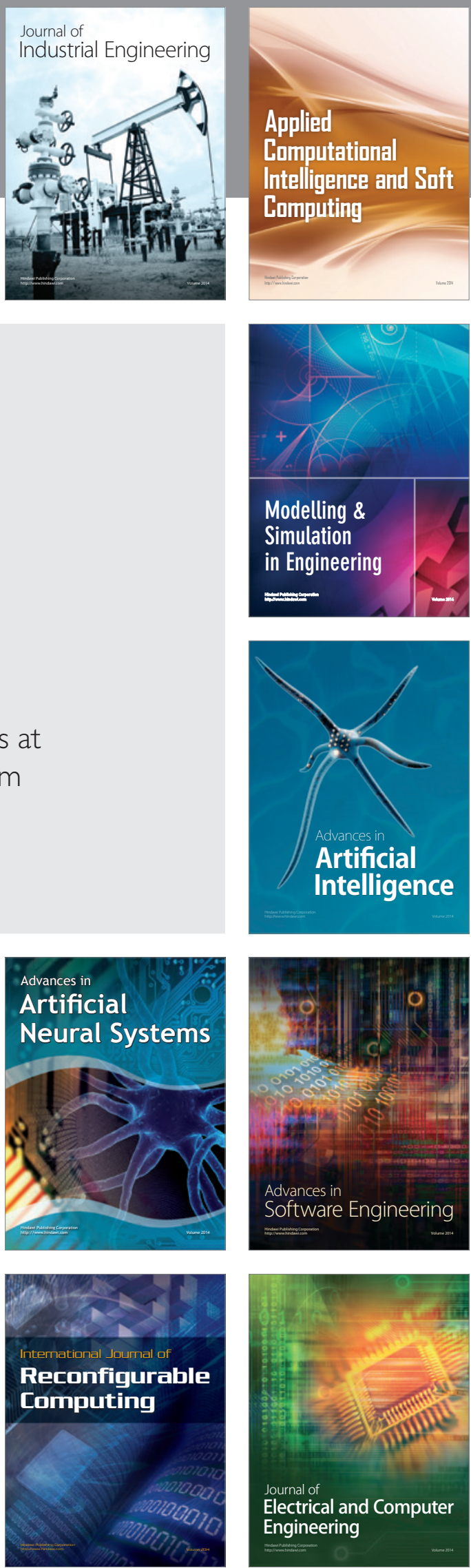